\title{
Geologia e Geomorfologia do Quaternário Costeiro do Estado do Rio Grande do Norte
}

\author{
Alcina Magnólia Franca Barreto’ (alcina@npd.ufpe.br), Kenitiro Suguio², Francisco Hilário Rego Bezerra³, \\ Sonia Hatsue Tatumi ${ }^{4}$, Márcio Yee ${ }^{4}$, Paulo César Fonseca Giannini \\ 'Departamento de Geologia - CTG - UFPE \\ Av. Acadêmico Hélio Ramos s/n, CEP 50740-530, Recife, PE, BRA \\ 2Departamento de Geologia Sedimentar e Ambiental - Instituto de Geociências - USP, São Paulo, SP, BRA \\ ${ }^{3}$ Departamento de Geologia - CCET - UFRN, Natal, RN, BRA \\ ${ }^{4}$ Departamento de Ensino Geral - FATEC, São Paulo, SP, BRA
}

Palavras-chave: Quaternário, depósitos costeiros, Rio Grande do Norte.

\section{RESUMO}

O objetivo deste trabalho é a apresentação de um mapa geológico-geomorfológico preliminar para o Quaternário costeiro do Estado do Rio Grande do Norte, com destaque para os depósitos eólicos. O mapa foi elaborado a partir de fotografias aéreas, escala 1:70.000, imagens de satélite (P/B, banda 4), escala 1:100.000, mapas topográficos e trabalhos de campo. Foram feitas datações ${ }^{14} \mathrm{C}$ em rochas praiais e depósitos de paleomangues e datações por termoluminescência em sedimentos eólicos e marinhos. Nos depósitos eólicos foram identificados três domínios geomorfológicos de dunas inativas e um de dunas ativas. Eles formaram-se no Quaternário a partir de retrabalhamento de areias da própria planície costeira e de sedimentos da Formação Barreiras. As idades TL de 36 amostras indicam que os depósitos eólicos foram formados durante seis intervalos principais: 390.000 - 326.000, 270.000 - 240.000, 210.000 - 150.000, 63.000 - 24.000, $11.000-9.000$ e, 6.500 anos presente. Essas idades sugerem sua deposição tanto durante estágios glaciais como interglaciais, relacionados a níveis relativos de mar baixos e altos respectivamente. Dois terraços marinhos foram identificados, com idades de 210.000 a 214.000 anos e 110.000 a 120.000 anos. O primeiro ocorre entre Natal e Baía Formosa, onde a costa se orienta na direção N - S; o segundo encontra-se no trecho da costa entre São Bento e Zumbi, com orientação E - W. Extensos depósitos de intermaré holocênicos, principalmente de arenitos praiais, estão localizados na costa orientada $\mathrm{N}-\mathrm{S}$ e apresentam idades entre $7.000-6.000$ anos AP. e $5.500-4.500$ anos AP.

Keywords: Rio Grande do Norte, Quaternary, coastal deposits.

\section{ABSTRACT}

This study presents the regional geological-geomorphological map of the Quaternary coastal record of Rio Grande do Norte State, Brazil, with emphasis on the aeolian deposits. The Quaternary record comprises aeolian, alluvial, and marine deposits (peat, intertidal, and tidal flat deposits). They were dated by thermoluminescence (TL) and ${ }^{14} \mathrm{C}$ methods. One active and three inactive aeolian geomorphological domains have been identified, which formed since the early Quaternary by the accumulation of sands from the coastal plain and such continental sources as the Barreiras Formation. TL dates indicate that aeolian deposits were formed in six main phases: 390,000 - 326,000, 270,000 - 240,000, 210,000 - 150,000, 63,000 - 24,000, $11,000-9,000,6,500$ years - till the present. These dates also indicate that aeolian deposits formed during both interglacial and glacial stages related to relative sea-level highstands and relative sea-level falls, respectively. Two marine terrace deposits have also been identified: a 210,000 - 214,000 year BP deposit between Natal and Baía Formosa on the N-S-trending coast; and a 120,000 - 114,000 year BP deposit between São Bento and Zumbi, mostly on the E-W-trending coast. Extensive Holocene intertidal deposits, mainly beachrocks, located on the N-S-trending coast exhibit ages of 7,000 - 6,000 and $5,500-4,500$ cal. yr BP. 


\section{INTRODUÇÃO E OBJETIVOS}

Os trabalhos existentes sobre a geologia dos sedimentos quaternários costeiros do Estado do Rio Grande do Norte enfatizam a descrição de depósitos eólicos e marinhos, baseados em critérios sedimentológicos e geomorfológicos. Os primeiros estudos relacionados aos depósitos eólicos litorâneos já aventavam a hipótese de existência de diferentes gerações de dunas eólicas no estado (e. g. Gomes et al., 1981; Nogueira et al., 1975) e esboçavam sucessões de idades relativas e inferências paleoclimáticas (Perrin e Costa, 1982) baseadas em contrastes de coloração das areias, de posição relativa à linha de costa atual e de feições morfológicas. Mais recentemente, Barreto et al. (1999) e Yee et al. (2000) dataram sedimentos eólicos por termoluminescência (TL), e Tatumi et al. (1999), por luminescência opticamente estimulada (LOE).

Os estudos sobre os depósitos marinhos quaternários deste trecho da costa brasileira foram iniciados no começo do século passado. Eles enfocaram as rochas praiais e sedimentos de intermarés (e. g. Branner, 1904; Srivastava e Corsino, 1984; Lucena, 1997), bem como os depósitos lagunares e/ou lacustres (e. g. Melo, 2000). Entretanto as primeiras idades absolutas só foram obtidas a partir da década de 1990 em rochas praiais (Oliveira et al., 1990; Bezerra et al., 1998; Bezerra e Vita-Finzi, 2000) e depósitos deltaicos (Silva, 1991).

Este trabalho, de caráter regional, tem por objetivo contribuir para a cartografia geológica dos sedimentos litorâneos do Rio Grande do Norte. O mapa apresenta a cronologia absoluta de depósitos costeiros para o Quaternário superior a partir da integração de idades previamente publicadas, e idades inéditas obtidas por TL $\mathrm{e}^{14} \mathrm{C}$, referentes principalmente a sedimentos eólicos e marinhos. Incluise também a tentativa de distinção entre depósitos costeiros pleistocênicos e holocênicos, através da cartografia de distintos terraços marinhos, rochas praiais e domínios eólicos (gerações de dunas) baseados em critérios geomorfológicos.

\section{MATERIAIS E MÉTODOS}

Para a confecção do mapa foram realizadas etapas de campo, combinadas com o estudo de cartas geológicas (Barbosa et al., 1974; DNPM/UFRN, 1998) e topográficas prévias, além de mosaicos de radar do projeto RADAMBRASIL (1:250.000) e outros produtos de sensoriamento remoto. A base de dados incluiu também obtenção de idades por ${ }^{14} \mathrm{C}$ em rochas praiais e datações por TL em depósitos eólicos e marinhos. As datações ao radiocarbono foram executadas pelo Beta Analytic Inc. (Florida, EUA) e as datações TL pelo Laboratório de Vidros e de Datação da Faculdade de
Tecnologia de São Paulo (FATEC - SP).

As amostras para datação TL foram coletadas do interior dos depósitos e protegidas da radiação solar. Em laboratório, as areias foram peneiradas para a obtenção da fração $0,180-0,062 \mathrm{~mm}$, tratada a seguir com ácidos (HF, $20 \%$ por 45 minutos e $\mathrm{HCl}, 20 \%$ por duas horas) para eliminação da influência da radiação alfa no sinal TL do quartzo, da película de óxido de ferro e de outros minerais leves menos resistentes indesejáveis, como as micas. Separaram-se os minerais pesados por afundamento em bromofórmio $\left(\mathrm{CHBr}_{3}\right)$. As leituras das paleodoses foram feitas em equipamento Daybreak, Nuclear and Medical Systems Incorporated, Model 1100 -series Automated TL/OSL, com filtros ópticos Schott BG-39 e Corning 7-59, à taxa de aquecimento linear de $10^{\circ} \mathrm{C} / \mathrm{seg}$., segundo o método da regeneração total (Aitken, 1998). A vantagem deste método é que o valor da paleodose não precisa ser extrapolado. As doses anuais de radiação natural local foram determinadas através da medida das concentrações de ${ }^{238} \mathrm{U},{ }^{235} \mathrm{U},{ }^{232} \mathrm{Th}$ e ${ }^{40} \mathrm{~K}$, obtidas pela Análise de Ativação de Nêutrons (AAN), no espectrômetro de radiação- $\gamma$ com detetor de germânio de alta resolução do Instituto de Pesquisas Energéticas e Nucleares/ Comissão Nacional de Energia Nuclear (IPEN/CNEN - SP).

\section{CONTEXTOS GEOLÓGICO E GEOMORFOLÓGICO COSTEIROS}

A área de estudo abrange o litoral do Rio Grande do Norte, com cerca de 350 km de extensão, entre $4^{0} 49^{\prime}$ a $6^{0} 29^{\prime}$ de latitude sul e $35^{\circ} 7^{\prime}$ a $37^{\circ} 15^{\prime}$ de longitude oeste. Geologicamente, é constituída por embasamento cristalino précambriano, por rochas sedimentares cretáceas das bacias sedimentares Potiguar e Pernambuco-Paraíba e por depósitos terrígenos miocênicos a pliocênicos da Formação Barreiras. Recobrindo estas unidades, ocorrem os depósitos marinhos, praiais, eólicos e aluviais do Quaternário (Figura 1).

Geomorfologicamente, a área estudada inclui-se na $r e$ gião nordestina ou litoral das barreiras de Silveira (1964), caracterizada pela constante presença dos depósitos sedimentares da Formação Barreiras, que formam uma superfície mais ou menos plana (tabuleiro), dissecada pela drenagem atual e suavemente inclinada para o oceano. Os afloramentos da Formação Barreiras separam a região costeira da sublitorânea e terminam, próximo ao mar, em falésias muitas vezes ativas (vivas). As planícies litorâneas de cristas praiais são pouco desenvolvidas ou inexistentes, o que denota mais tendência à erosão que à sedimentação, conforme evidenciado pela presença constante de falésias de rochas mais antigas, com até 30 - $40 \mathrm{~m}$ de altura, não somente da Formação Barreiras, mas também de depósitos de paleopraias quaternárias, na forma de terraços de constru- 


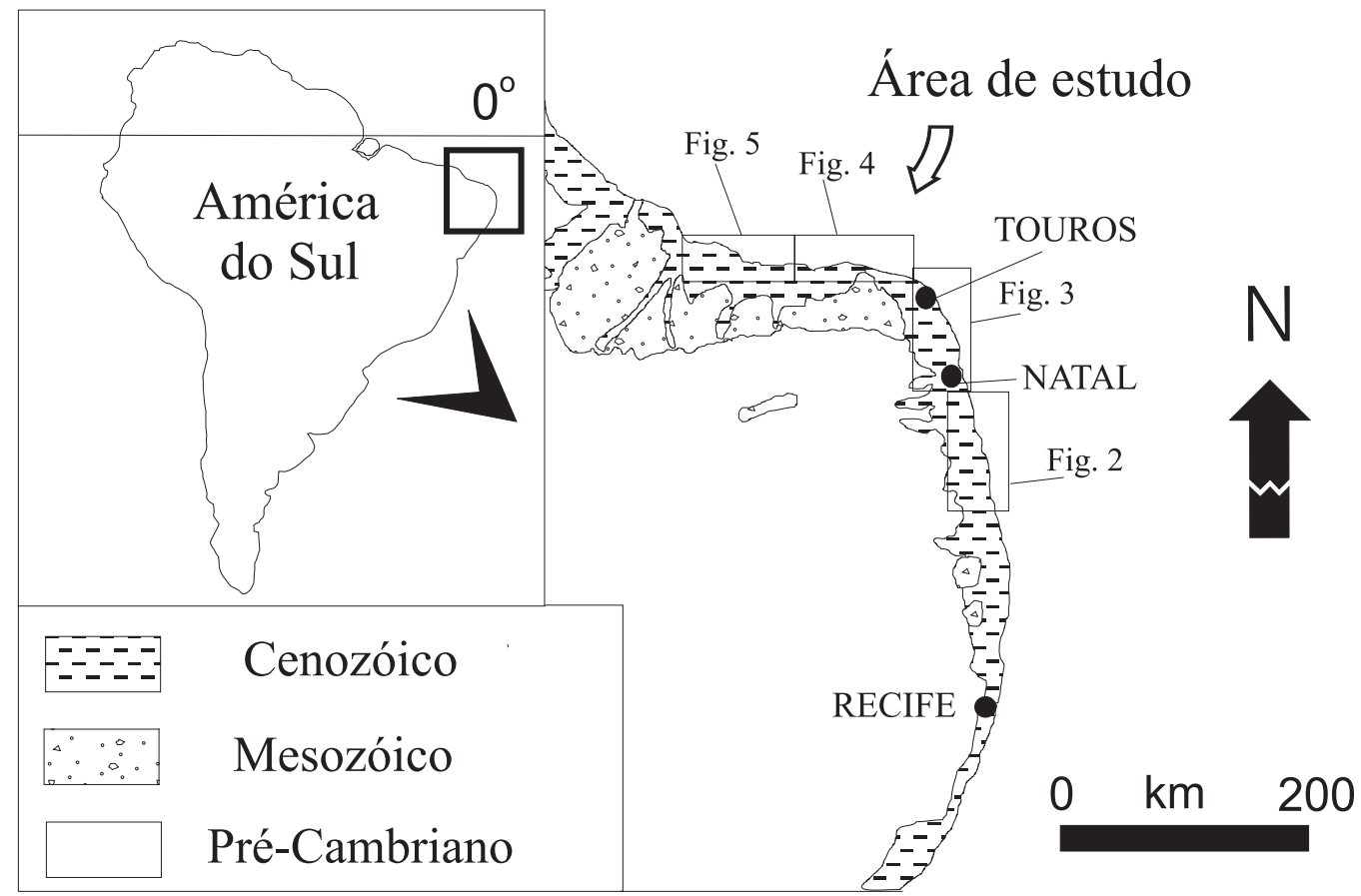

Figura 1. Área de estudo e geologia regional.

ção marinha, e de paleodunas. O retrabalhamento de sedimentos praiais por processos eólicos é marcante, a amplitude de marés é de mesomaré (2 a $4 \mathrm{~m}$ ) e, segundo Bezerra et al. (1998) e Bezerra e Vita-Finzi (2000), a tectônica quaternária tem sido ativa na região.

\section{RESULTADOS E DISCUSSÃO}

Os sedimentos quaternários mapeados ao longo da costa compreendem depósitos eólicos (dunas ativas e inativas e lençóis de areia inativos), e marinhos (depósitos regressivos pleistocênicos, rochas praiais holocênicas e depósitos de planície de maré atual).

\section{Depósitos Eólicos}

No litoral do Rio Grande do Norte, ocorrem dunas ativas e inativas. Para a caracterização das dunas inativas utilizaram-se três tipos de critérios:

a. critérios morfológicos, que incluem a possível modificação dos ângulos de inclinação de barlavento e sotavento, a presença de ravinas e leques de areia, o grau de dissecação e a tendência para a redução da altura da duna e obliteração das formas deposicionais originais, todos crescentes com a idade; b. critérios sedimentológicos, baseados na presença de silte e argila pedogenéticos e no grau de seleção da areia;

c. critérios biológicos, que envolvem principalmente a presença e a densidade de cobertura vegetal, que na área variou de aberta, do tipo restinga (maior parte do estado), até vegetação densa de mata Atlântica (sul do estado). Para efeito de mapeamento, foi feita a distinção de pelo menos quatro domínios de dunas eólicas, dos quais três são inativos. Dada a possibilidade de existência de correlação positiva entre a maioria dos critérios de caracterização de dunas inativas e as idades relativas, os domínios reconhecidos podem também ser considerados como possíveis gerações de dunas (Figuras 2, 3, 4 e 5).

Ocorrem formas barcanas, barcanóides e parabólicas, com diferentes graus de preservação nos diferentes domínios eólicos. O primeiro domínio corresponde ao das dunas ativas (DA), caracterizado pela predominância de barcanas isoladas e cristas barcanóides associadas a frentes parabólicas transgressivas, com pouca ou nenhuma vegetação. $\mathrm{O}$ segundo domínio é o das dunas inativas com formas nítidas (DIn). Corresponde a dunas parabólicas compostas, vegetadas e com morfologia nítida nas imagens de satélite e fotografias aéreas. Este domínio inclui também dunas parabólicas ativas, parcialmente vegetadas e com migração lenta. O terceiro domínio, das dunas inativas com formas tênues 


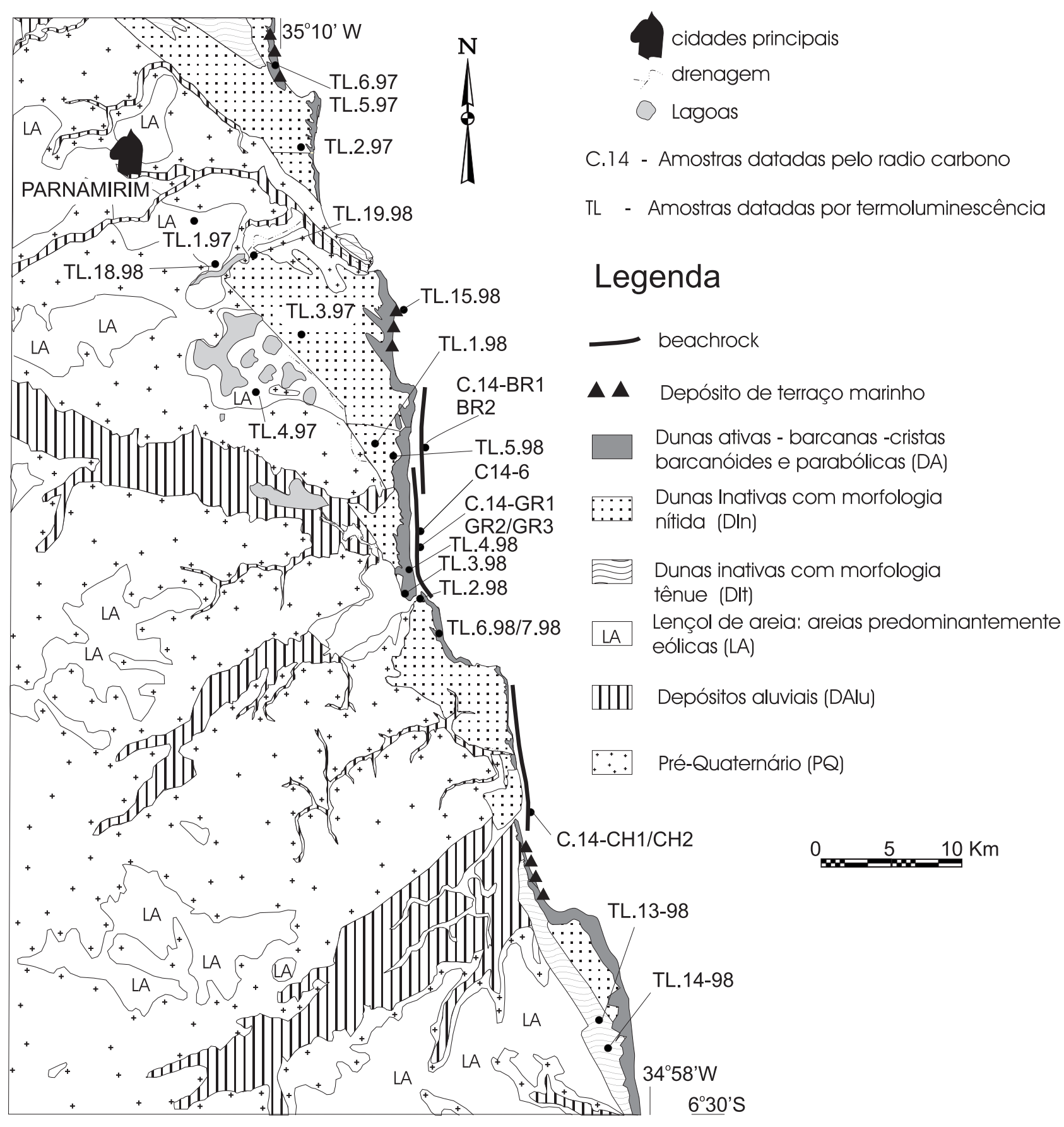

Figura 2. Mapa geológico do Quaternário costeiro do Rio Grande do Norte. Setor extremo sul do estado a norte de Parnamirim. 


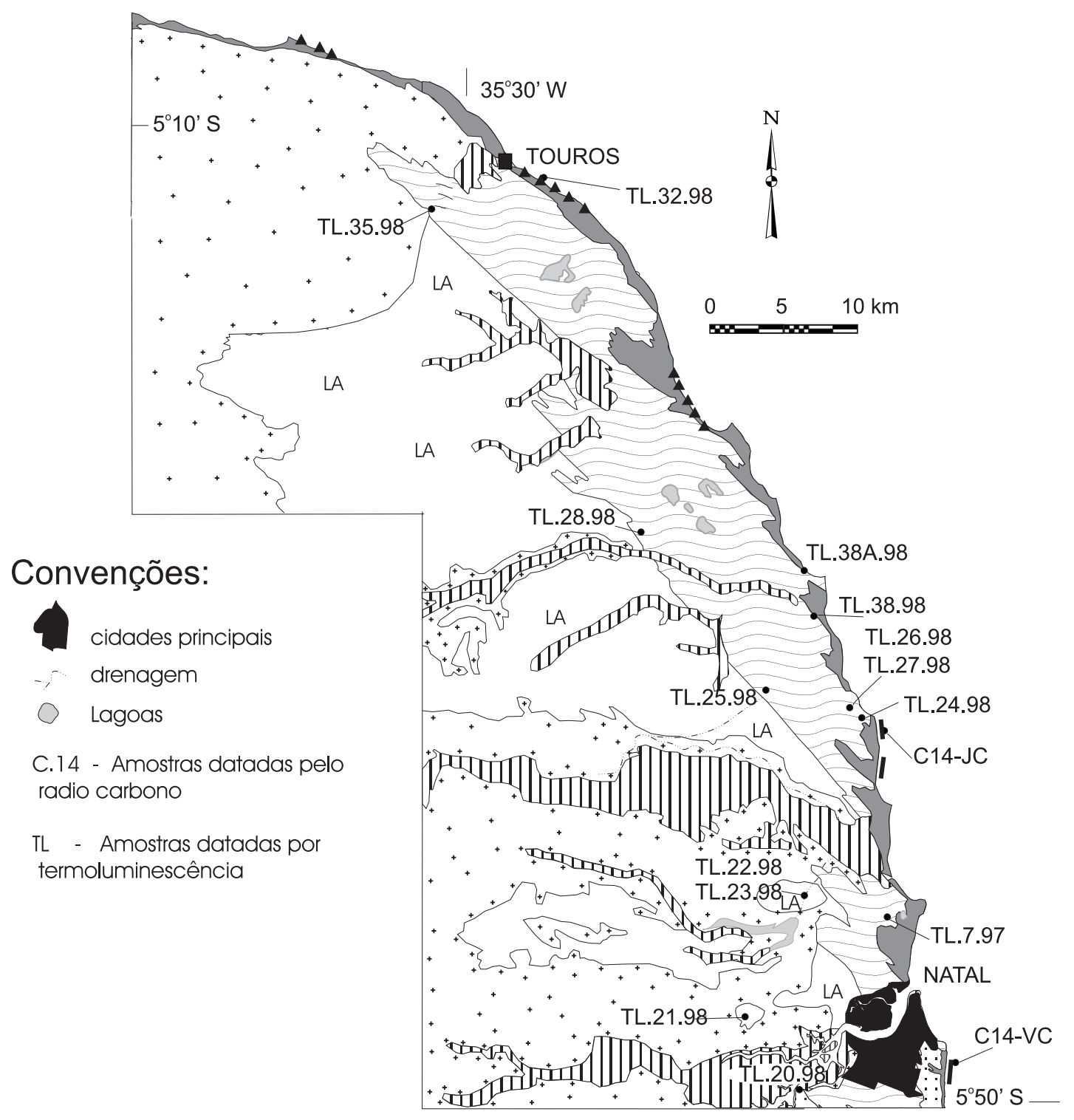

\section{Legenda}

$\Delta$ Depósito de terraço marinho Dunas ativas - barcanas - cristas barcanóides - parabólicas (DA)

:.:.: Dunas inativas com morfologia nítida (DIn)

EDunas inativas com morfologia tênue (Dlt)

$$
\begin{aligned}
& \text { LA Lençlicas de areia: areias predominantemente } \\
& \text { eólicas morfologia nítida (LA) } \\
& \text { WIII Depósitos aluviais (DAlu) } \\
& \therefore: \text { Pré-quaternário }(\mathrm{PQ})
\end{aligned}
$$

Figura 3. Mapa geológico do Quaternário costeiro do Rio Grande do Norte. Setor Natal a oeste de Touros. 


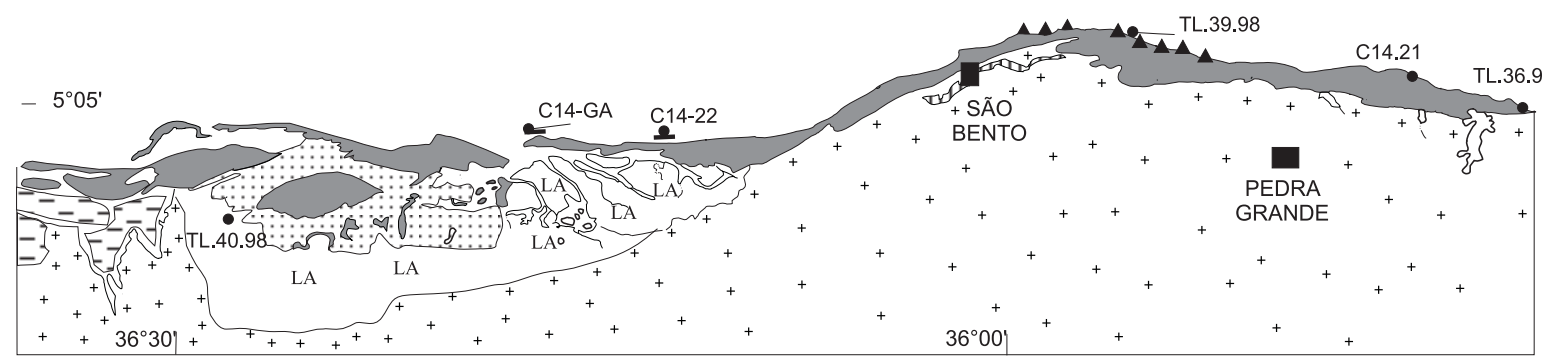

\section{Legenda}
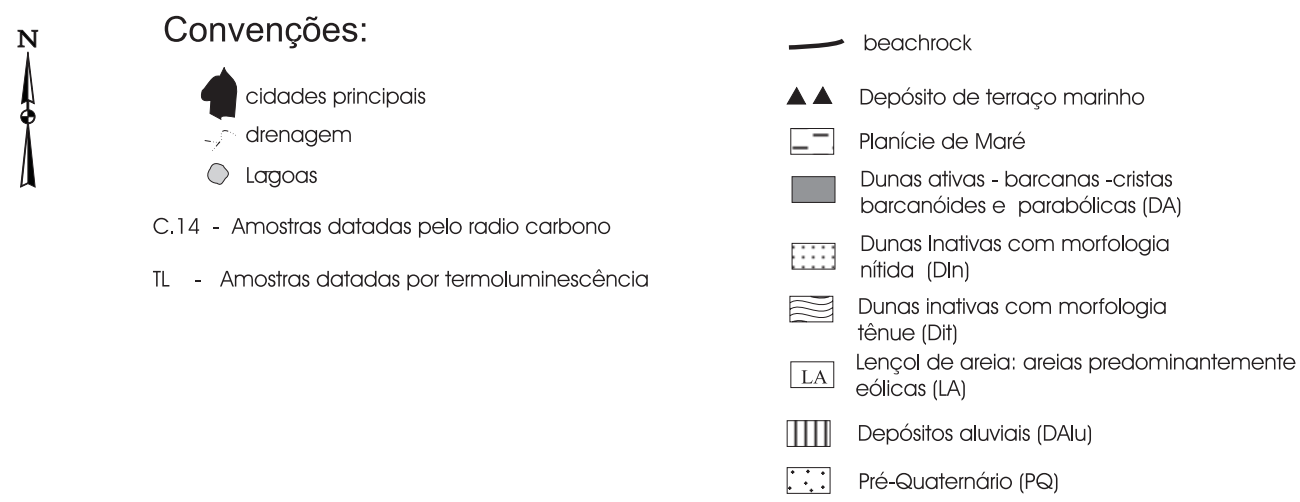

Figura 4. Mapa geológico do Quaternário costeiro do Rio Grande do Norte. Setor oeste de Touros a leste de Macau.

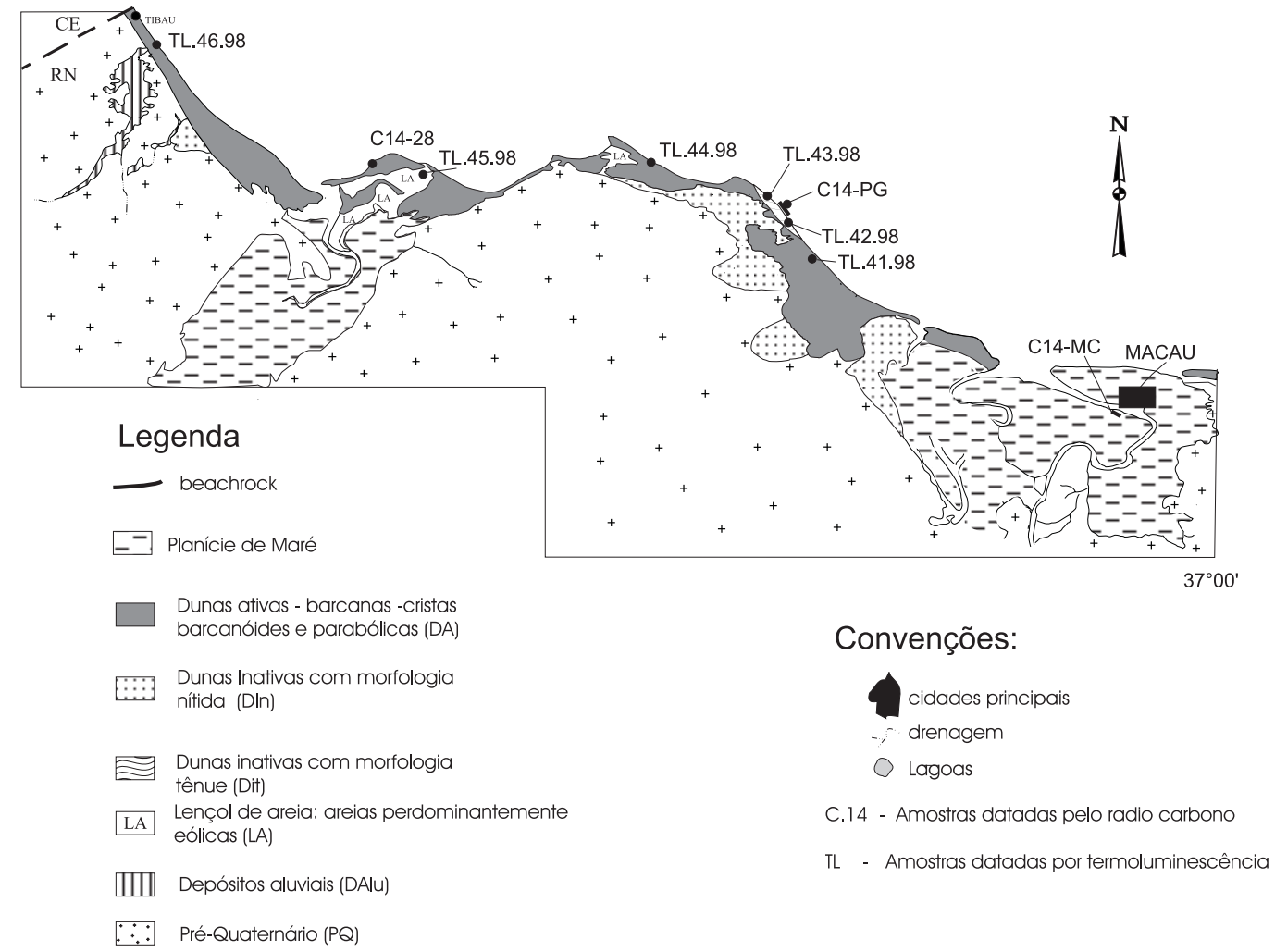

Figura 5. Mapa geológico do Quaternário costeiro do Rio Grande do Norte. Setor leste de Macau a Tibau. 
(DIt), é constituído predominantemente de dunas do tipo parabólicas compostas e simples, além de longitudinais, estas últimas correspondentes possivelmente a rastros lineares residuais (trailing ridges) de dunas parabólicas. $\mathrm{O}$ quarto domínio, também inativo, é o dos lençóis de areia (LA), constituído por formas mais tênues ou dissipadas que os demais. Feições de reativação são visíveis em imagens de satélites em todos os domínios de dunas inativas.

As idades encontradas nos quatro domínios eólicos, obtidas por TL (Tabela 1 e Figura 6), representam os tempos decorridos após a última exposição das areias aos raios solares, seja durante sua deposição, seja em eventos posteriores de erosão e/ou retrabalhamento. As idades variaram de 390.000 anos até o presente. O domínio de dunas inativas com formas nítidas (DIn) apresenta idades de 6.000 anos a poucas dezenas ou centenas de anos. As idades mais antigas neste domínio coincidem aproximadamente com o máximo nível relativo do mar (NRM) holocênico na costa nordeste brasileira. As idades mais novas corresponderiam a porções recentemente expostas ou reativadas destas paleodunas. Os domínios de dunas inativas com formas tênues (DIt) apresentam idades muito variáveis, desde 89.000 anos até o Recente (Holoceno). Das 14 amostras datadas deste domínio, três apresentam idades coincidentes com a passagem Pleistoceno-Holoceno (11.000 a 9.000 anos). O domínio dos lençóis de areia (LA) reúne idades desde 390.000 até 5.700 anos. As idades TL mais novas obtidas nos dois domínios DIt e LA podem representar retrabalhamento dos depósitos eólicos, sugerindo que também nessas unidades ocorreram reativações eólicas.

Possíveis discordâncias entre depósitos eólicos, reapresentados por contatos abruptos entre dunas de diferentes texturas e colorações, foram estabelecidas no campo. Posteriormente, os hiatos entre estes depósitos foram evidenciados pelos resultados de datações por TL (Figuras 6.6, 6.7, 6.10, 6.16 e 6.17, 6.19, 6.23 e 6.28).

As atividades eólicas durante o Pleistoceno Superior parecem ter sido bastante freqüentes na área (18 amostras ou $50 \%$ do total), provavelmente intercaladas por vários momentos de estabilidade parcial e fixação de dunas. O início do Holoceno é marcado por quatro amostras datadas entre 11.000 e 9.000 anos. Nova fase de atividade eólica teria ocorrido a partir de 6.500 anos AP. (Holoceno médio), conforme sugerido pelas idades de 13 amostras que variaram entre 6.500 e 50 anos. As 5 amostras com idades mínimas inferiores a 200 anos evidenciam atividade recente de areias eólicas, associada à dinâmica dos campos de dunas ativas da área de estudo, ou retrabalhamento de dunas antigas. A baixa coerência entre os domínios geomorfológicos eólicos e as idades obtidas é sugestiva de que a sucessão de fases de reativação ou erosão de dunas previamente estabilizadas pode ter sido complexa.
Com base na distribuição das idades ao longo do tempo, torna-se possível vislumbrar pelo menos seis fases mais importantes de atividade eólica, seguidas de fixação: 390.000 a 326.000 anos (duas amostras), 240.000 a 270.000 anos (três amostras), 210.000 a 150.000 anos (três amostras), 63.000 a 24.000 anos (nove amostras), 11.000 a 9.000 anos (cinco amostras) e 6.500 anos até hoje (13 amostras).

As dunas inativas, formadas pelo menos desde o Quaternário superior, teriam resultado da acumulação de areias vindas tanto das praias, quanto das planícies costeiras ou aluviais expostas. A contribuição da Formação Barreiras como rocha-fonte deve ter variado em função direta do grau de exposição e dissecação. Desse modo ela teria atuado como fonte principalmente em momentos de nível do mar mais baixo que o atual, durante os períodos glaciais. Giannini et al. (2001) apresentam dados texturais e mineralógicos que suportam estas idéias. Com base nas idades aqui apresentadas, a geração de dunas eólicas teria ocorrido tanto durante os contextos de NRM alto (estádios interglaciais), como nos de NRM baixo (estádios glaciais). Com base em resultados sedimentológicos de Giannini et al. (2001), os sedimentos eólicos depositados em contexto de mar baixo teriam sido influenciados pela erosão mais efetiva da Formação Barreiras devido ao rebaixamento do nível de base. As dunas deste contexto seriam formadas a partir do retrabalhamento de areias da planície exposta na regressão forçada. A maior importância da Formação Barreiras como rocha-fonte imediata nos períodos de nível do mar muito mais baixo do que o atual explicaria a formação de dunas de coloração mais vermelha e de granulação mais grossa nesses períodos.

\section{Depósitos Marinhos}

Os sedimentos marinhos cartografados neste trabalho compreendem os depósitos de intermarés a inframarés pleistocênicos, depósitos de intermarés a inframarés holocênicos (rochas praiais) e depósitos de planície de maré atual.

Os depósitos pleistocênicos de intermarés a inframarés afloram na forma de falésias em dois setores do litoral do estado, cada qual apresentando tipos litológicos e idades distintas. Ambos apresentam contatos basais erosivos com a Formação Barreiras e acham-se recobertos por dunas inativas ou ativas. $\mathrm{O}$ depósito mais antigo aflora entre Natal e Baía Formosa (Figura 2), com altitude máxima de $7 \mathrm{~m}$, sendo constituído por arenitos quartzosos mais ou menos argilosos a conglomeráticos. As idades TL indicam que este depósito foi formado entre 215.000 e 206.000 anos (Tabela 2). O depósito mais novo é composto por arenitos biodetríticos, grossos a muito grossos, localmente conglomeráticos, com intensa cimentação carbonática, 
Tabela 1. Localizações, cores, doses anuais de radiação local, paleodoses e idades obtidas por TL das amostras de dunas eólicas costeiras do Rio Grande do Norte. As amostras com asteriscos foram corrigidas pelas doses anuais de radiação local por diferenças de teores de K, de Barreto et al. (1999). Dln - duna inativa com morfologia nítida em fotografias aéras e imagens de satélite. Dlt - duna inativa com morfologia tênue. LA - lençol de areia (depósitos eólicos sem morfologia preservada).

\begin{tabular}{|c|c|c|c|c|c|c|}
\hline Amostra & $\begin{array}{c}\text { Domínio } \\
\text { eólico }\end{array}$ & $\begin{array}{c}\text { Localização } \\
\text { (UTM ) }\end{array}$ & Cor & $\begin{array}{c}\text { Dose anual } \\
(\mu \mathrm{Ga} / \mathrm{ano})\end{array}$ & $\begin{array}{c}\text { Paleodose } \\
\text { (Ga) }\end{array}$ & $\begin{array}{l}\text { Idade } \\
\text { (anos) }\end{array}$ \\
\hline 2.97 & DIn & $2606-9349$ & Laranja pálido & $557 \pm 6$ & $0,12 \pm 0,01$ & $220 \pm 20$ \\
\hline 3.97 & DIn & $2607-9333$ & Marrom claro & $463 \pm 4$ & $2,8 \pm 0,3$ & $3900 \pm 700$ \\
\hline 1.98 & DIn & $2643-9327$ & Marrom amarelado & $463 \pm 4$ & $2,8 \pm 0,3$ & $6000 \pm 600$ \\
\hline 5.98 & DIn & $2657-9326$ & Marrom amarelado & $463 \pm 4$ & $2+0,3$ & $4600+600$ \\
\hline 19.98 & DIn & $2569-9339$ & Laranja amarelado & - & $0,1 \pm 0,01$ & $1-50$ \\
\hline 20.98 & DIn & $2482-9355$ & Marrom amarelado & - & $0,1 \pm 0,01$ & $1-50$ \\
\hline 25.98 & DIt & $2438-9385$ & Laranja amarelado & - & $0,5 \pm 0,02$ & $1-200$ \\
\hline 7.97 & Dlt & $2556-9368$ & Marrom amarelado & $706 \pm 13$ & $0,9 \pm 0,3$ & $3500 \pm 1200$ \\
\hline 13.98 & DIt & $2676-9290$ & Marrom amarelado & $419 \pm 4$ & $14 \pm 1$ & $33000 \pm 3000$ \\
\hline 14.98 & Dlt & $2776-9290$ & Marrom moderado & $419 \pm 4$ & $11 \pm 1$ & $26000 \pm 3000$ \\
\hline 24.98 & Dlt & $5523-9382$ & Marrom amarelado & $430 \pm 7$ & $22 \pm 3$ & $51000 \pm 7200$ \\
\hline 26.98 & Dlt & $2508-9384$ & Laranja amarelado & $513 \pm 7$ & $11 \pm 1$ & $21400 \pm 2000$ \\
\hline 27.98 & DIt & $2508-9384$ & Laranja escuro & $513 \pm 7$ & $18 \pm 1$ & $35000 \pm 2000$ \\
\hline 28.98 & Dlt & $2352-9397$ & Marrom claro & $1185 \pm 17$ & $13 \pm 0.5$ & $11000 \pm 500$ \\
\hline 35.98 & DIt & $2196-9421$ & Marrom acinzentado & - & $0,1 \pm 0,01$ & $1-50$ \\
\hline 36.98 & Dlt & $2164-9431$ & Marrom avermelhado & $1414 \pm 16$ & $127 \pm 6$ & $89700 \pm 6000$ \\
\hline 41.98 & Dlt & $7405-9434$ & Marrom avermelhado & $1623 \pm 17$ & $40,1 \pm 0,4$ & $24700 \pm 5000$ \\
\hline 42.98 & DIt & $7392-9447$ & Marrom claro & $596 \pm 20$ & $1,5 \pm 0,1$ & $2500 \pm 200$ \\
\hline 43.98 & DIt & $7374-9451$ & Marrom claro & $678 \pm 20$ & $6,2 \pm 0,2$ & $9100 \pm 600$ \\
\hline 44.98 & Dlt & $7482-9454$ & Marrom avermelhado & $437 \pm 17$ & $4,1 \pm 0,2$ & $9400 \pm 800$ \\
\hline 46.98 & LA & $6935-9465$ & Marrom avermelhado & $857 \pm 16$ & $128 \pm 3$ & $149000 \pm 6000$ \\
\hline 1.97 & LA & $2537-9349$ & Marrom claro & $557 \pm 6$ & $145 \pm 2$ & $35000 \pm 5000$ \\
\hline 4.97 & LA & $2593-9331$ & Marrom amarelado & $963 \pm 9$ & $0,4 \pm 0,1$ & $4200 \pm 100$ \\
\hline 2.98 & LA & $2685-9316$ & Laranja acinzentado & $475 \pm 6$ & $185 \pm 5$ & $390000 \pm 10000$ \\
\hline 3.98 & LA & $2685-9316$ & Laranja acinzentado & $466 \pm 7$ & $112 \pm 3$ & $240000 \pm 10000$ \\
\hline 4.98 & LA & $2680-9313$ & Marrom amarelado & $463 \pm 4$ & $4+0,3$ & $9150+900$ \\
\hline 6.98 & LA & $2696-9313$ & Marrom claro & $332 \pm 6$ & $70+2$ & $210000+30000$ \\
\hline 7.98 & LA & $2696-9313$ & Marrom amarelado & $629 \pm 7$ & $150 \pm 7$ & $240000 \pm 10000$ \\
\hline 18.98 & LA & $2567-9338$ & Marrom amarelado & $463 \pm 5$ & $3 \pm 0,5$ & $6500 \pm 500$ \\
\hline 21.98 & LA & $2482-9359$ & Marrom avermelhado & $1534 \pm 20$ & $500 \pm 2$ & $326000 \pm 5600$ \\
\hline 22.98 & LA & $2482-9355$ & Marrom avermelhado & $706 \pm 13$ & $45 \pm 3$ & $64000 \pm 5000$ \\
\hline 23.98 & LA & $2482-9365$ & Marrom claro & $463 \pm 4$ & $5,3 \pm 0,5$ & $11000 \pm 1000$ \\
\hline 38.98 & LA & $2493-9390$ & Laranja acinzentado & $315 \pm 14$ & $141 \pm 5$ & $190000 \pm 10000$ \\
\hline 38a.98 & LA & $2486-9394$ & Laranja acinzentado & $419 \pm 4$ & $84 \pm 3$ & $270000 \pm 20000$ \\
\hline 40.98 & LA & - & Laranja acinzentado & $793 \pm 10$ & $4,5 \pm 0,4$ & $5700 \pm 600$ \\
\hline 45.98 & LA & $7137-9454$ & Marrom amarelado & $348 \pm 11$ & $22,0 \pm 0,4$ & $63000 \pm 3000$ \\
\hline
\end{tabular}




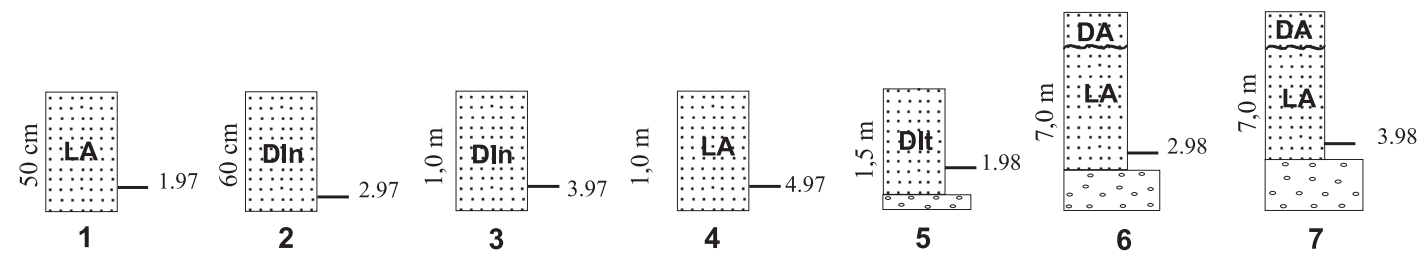

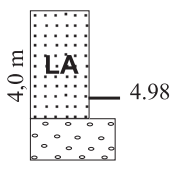

8

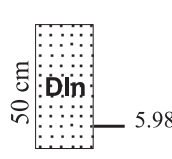

9

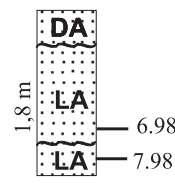

10

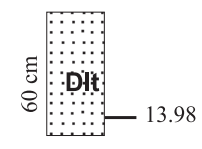

11

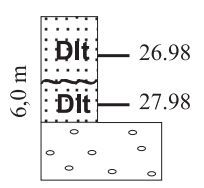

17

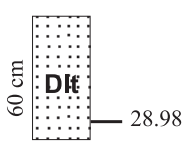

18

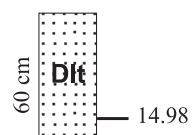

12

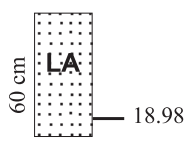

13

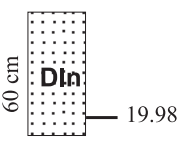

14

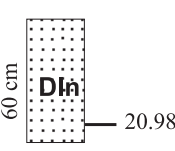

15

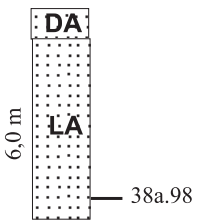

21

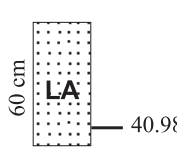

22

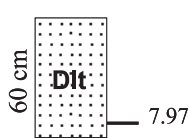

29

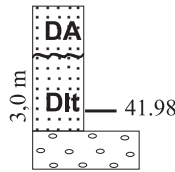

23

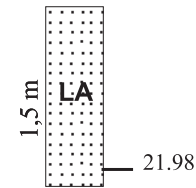

30

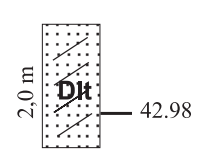

24

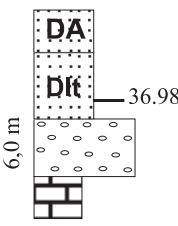

19

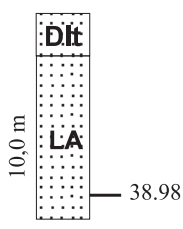

20

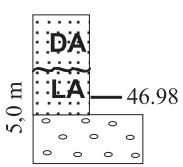

28

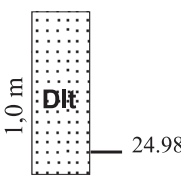

31

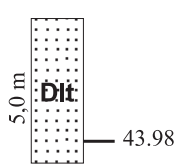

25

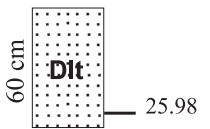

32

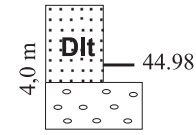

26

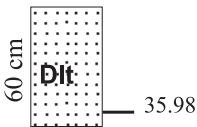

33
DA Dunas ativas

Dunas inativas de morfologia nítida

Dit: Dunas inativas de morfologia tênue

:

$\begin{aligned} & \because \\ & \vdots\end{aligned}:$ Formação Barreiras

Formação Jandaíra
Superfície discordante

$\because::$ Estrutura maciça

$\because$ Estratificação cruzada

42.98 Número da amostra

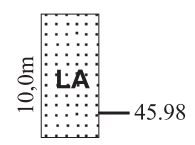

27

Figura 6. Seções estratigráficas de depósitos eólicos datados por TL. 
aflorando no trecho entre Zumbi (Figura 3) e São Bento do Norte (Figura 4). A altitude dos afloramentos varia entre $3 \mathrm{e}$ $20 \mathrm{~m}$; em algumas localidades, como Zumbi, os afloramentos ocorrem em meio às dunas eólicas, situadas até cerca de $200 \mathrm{~m}$ continente adentro. Duas datações TL indicam que este depósito formou-se entre 117.000 e 110.000 anos (Tabela 2). Barreto et al. (2001a e 2001b) e Suguio et al. (2001) apresentam detalhes sobre esses depósitos sedimentares e suas relações com a variação do NRM durante o Pleistoceno superior.

As rochas praiais afloram ao longo de toda a costa do Rio Grande do Norte (Figuras 2 a 5) e apresentam idades que variam do Holoceno médio até o presente (Tabela 3). A granulometria varia de areia fina a conglomerática. Entre as estruturas sedimentares, têm-se principalmente estratificações cruzadas acanaladas e estratificação cruzada de ângulo baixo (séries cuneiformes de estratificações plano-paralelas), relacionadas aos depósitos de intermaré inferior a inframaré e depósitos de inframaré superior, respectivamente (Bezerra et al., 1998). As idades dos corpos com extensão lateral quilométrica podem ser reunidas em dois grupos. O primeiro é exemplificado pelas rochas praiais das praias de Guaraíra e Barra de Cunhaú (Figura 2), ambas com cerca de $3 \mathrm{~km}$ de extensão, cujas idades variam entre 5.600 e 7.400 anos cal AP. O outro grupo apresenta idades entre 4.380 e 5.310 anos cal AP., como as rochas praiais da Praia de Barreta, também com mais de $3 \mathrm{~km}$ de extensão (Figura 2). Estes corpos parecem estar associados ao momento de desaceleração da subida do NRM na área de estudo.

As planícies de marés se desenvolveram no setor de orientação E-W nos estuários dos rios Açu e Mossoró (Figuras 4 e 5). A Tabela 3 contém os resultados de idades ${ }^{14} \mathrm{C}$ convencionais, bem como informações quanto à altura estimada do NRM, ao número de laboratório e aos materiais datados.

Tabela 2. Idades obtidas por TL de terraços marinhos pleistocênicos.

\begin{tabular}{ccccc}
\hline $\begin{array}{c}\text { Amostra } \\
\text { TL }\end{array}$ & $\begin{array}{c}\text { Localização } \\
\text { (UTM) }\end{array}$ & $\begin{array}{c}\text { Paleodose } \\
(\mathbf{G a})\end{array}$ & $\begin{array}{c}\text { Dose anual } \\
(\mu \mathrm{Ga} / \mathrm{ano})\end{array}$ & $\begin{array}{c}\text { Idade } \\
\text { (anos) }\end{array}$ \\
\hline 5.RN & $2584-9351$ & $89 \pm 2$ & $415 \pm 4$ & $215000 \pm 7000$ \\
$6 . \mathrm{RN}$ & $2584-9351$ & $70 \pm 9$ & $332 \pm 6$ & $211000 \pm 31000$ \\
$11.98 \mathrm{RN}$ & $2756-9297$ & $59 \pm 5$ & $332 \pm 6$ & $177000 \pm 20000$ \\
15.98 & $2666-9330$ & $71 \pm 3$ & $344 \pm 3$ & $206000 \pm 11000$ \\
39.98 & - & $109 \pm 4$ & $999 \pm 28$ & $110000 \pm 10000$ \\
\hline
\end{tabular}

Tabela 3. Idades ${ }^{14} \mathrm{C}$ obtidas em conchas de arenitos praiais e paleomangues. Fontes: 1. Este trabalho. 2. Bezerra et al. (1998).

\begin{tabular}{|c|c|c|c|c|c|c|}
\hline $\begin{array}{l}\text { Amostral } \\
\text { Fonte }\end{array}$ & $\begin{array}{l}\text { Número de } \\
\text { laboratório }\end{array}$ & $\begin{array}{c}\text { Altura do paleonível } \\
\text { marinho (metro) }\end{array}$ & $\begin{array}{c}\text { Natureza da amostra } \\
\text { (indicador de nível do mar) }\end{array}$ & $\begin{array}{l}{ }^{13} \mathrm{C} /{ }^{12} \mathrm{C} \\
{ }^{0} /_{00}\end{array}$ & $\begin{array}{l}\text { Idade }{ }^{14} \mathrm{C} \\
\text { (anos AP) }\end{array}$ & $\begin{array}{l}\text { Idade calibrada } \\
\qquad(\mathrm{AP} \text { a } 2 \sigma)\end{array}$ \\
\hline $\mathrm{C} 14-21 /(1)$ & Beta 121267 & $2,1 \pm 1,0$ & Conchas em rochas praiais & - & $3960 \pm 70$ & $4140-3760$ \\
\hline $\mathrm{C} 14-22 /(1)$ & Beta 121268 & $1,2 \pm 0,5$ & Conchas em rochas praiais & - & $2950 \pm 70$ & $2850-2550$ \\
\hline C14-28/(1) & Beta 121274 & $0,6 \pm 1,0$ & Coral em rochas praiais & - & $3250 \pm 70$ & $3260-2860$ \\
\hline$P G /(2)$ & UCL 423 & $0,6 \pm 1,0$ & Conchas em rochas praiais & 0,54 & $2700 \pm 80$ & $2680-2190$ \\
\hline $\mathrm{MC} 1 /(2)$ & UCL 345 & $1,8 \pm 1,0$ & Conchas em rochas praiais & 0,48 & $1600 \pm 40$ & $1250-1060$ \\
\hline $\mathrm{GA} /(2)$ & UCL 416 & $1,1 \pm 1,0$ & Conchas em rochas praiais & 0,3 & $3550 \pm 100$ & $3680-3210$ \\
\hline C14-6/(1) & Beta 121253 & $0,8 \pm 1,0$ & Conchas em rochas praiais & - & $5470 \pm 60$ & $5950-5700$ \\
\hline $\mathrm{JC} /(2)$ & UCL 413 & $0,5 \pm 1,0$ & Conchas em rochas praiais & 0,27 & $4950 \pm 150$ & $5600-4840$ \\
\hline $\mathrm{VC} /(2)$ & UCL 430 & $-0,7 \pm 1,0$ & Conchas em rochas praiais & $-0,5$ & $6300 \pm 200$ & $7240-6300$ \\
\hline $\mathrm{BR} 1 /(2)$ & UCL 403 & $2,2 \pm 1,0$ & Conchas em rochas praiais & $-1,32$ & $4700 \pm 140$ & $5310-4560$ \\
\hline $\mathrm{BR} 2 /(2)$ & UCL 404 & $1,8 \pm 1,0$ & Conchas em rochas praiais & $-1,32$ & $4500 \pm 120$ & $4970-4380$ \\
\hline GR1/(2) & UCL 419 & $0,2 \pm 1,0$ & Conchas em rochas praiais & - & $5600 \pm 170$ & $6340-5600$ \\
\hline $\mathrm{GR} 2 /(2)$ & UCL 421 & $0,0 \pm 1,0$ & Conchas em rochas praiais & - & $6550 \pm 210$ & $7460-6550$ \\
\hline GR3/(2) & UCL 405 & $0,7 \pm 1,0$ & Conchas em rochas praiais & $-0,5$ & $5950 \pm 170$ & $6730-5980$ \\
\hline $\mathrm{CH} 2 /(2)$ & UCL 432 & $1,7 \pm 1,0$ & Conchas em rochas praiais & $-0,77$ & $5400 \pm 170$ & $6170-5440$ \\
\hline $\mathrm{CH} 1 /(2)$ & UCL 414 & $1,5 \pm 1,0$ & Conchas em rochas praiais & $-2,25$ & $6550 \pm 210$ & $7460-6550$ \\
\hline
\end{tabular}




\section{CONSIDERAÇÕES FINAIS}

Foram reconhecidos quatro domínios geomorfológicos, um de dunas ativas (DA) e três com o predomínio de dunas inativas (DIn, DIt e LA), mas com indícios de reativações recentes. As idades obtidas dentro de cada um dos domínios geomorfológicos de depósitos eólicos reconhecidos apresentaram grande variação (Tabela 1). Apesar disso, os dados disponíveis não permitem descartar a hipótese de correlação destes domínios com diferentes gerações eólicas uma vez que as variações encontradas possam decorrer da grande extensão da área amostrada. Com base na distribuição das idades ao longo do tempo, é possível que pelo menos seis fases mais importantes de atividade eólica, seguidas de fixação, tenham ocorrido na área: 390.000 a 326.000 anos, 240.000 a 270.000 anos, 210.000 a 150.000 anos, 63.000 a 24.000 anos, 11.000 a 9.000 anos e 6.500 anos até o presente. A partir das idades TL, pode-se supor que as dunas tenham se estabelecido tanto em contexto de NRM alto quanto sob NRM baixo, tendo como área fonte imediata, respectivamente, as areias de praia e os sedimentos costeiros e aluviais expostos pela regressão.

Os terraços marinhos apresentam dois conjuntos de idades pleistocênicas sendo o mais antigo, com 210.000 214.000 anos (Ponta Negra, Barra de Tabatinga e Baía Formosa) e o mais novo, com 120.000 - 114.000 anos (São Bento, Touros, Zumbi). As rochas praiais vêm sendo formadas continuamente por todo o litoral do Rio Grande do Norte, desde o Holoceno médio até o Presente, mas os corpos mais extensos apresentam as idades mais antigas, isto é, entre 5.600 - 7.400 anos cal AP e 4.380 - 5.310 anos cal AP, e podem representar o momento de desaceleração da subida do NRM, em escala milenar. As planícies de marés estão desenvolvidas mais conspicuamente na faixa costeira de orientação E - W (a oeste de Touros), e os exemplos mais representativos encontram-se nos estuários dos rios Açu e Mossoró.

\section{AGRADECIMENTOS}

À Fundação de Amparo à Pesquisa do Estado de São Paulo (FAPESP), pelo auxílio financeiro que permitiu a realização deste trabalho. Aos revisores da revista pelas sugestões ao manuscrito e à Sra. Maristela Prestes Severino pela conferência das referências bibliográficas.

\section{REFERÊNCIAS BIBLIOGRÁFICAS}

AITKEN, M. J. An introduction to optical dating - the dating of Quaternary sediments by of the photon-stimulated luminescence. Oxford: University Press, 1998. 230p. BARBOSA, J. A.; BRAGA, A. P. G.; BEZERRA, M. A.; GO-
MES, J. A. V. Projeto Leste da Paraíba e Rio Grande do Norte: folhas SB-25-Y-A e SB-25-V-C. Recife: DMPM/ CPRM, 1974.

BARRETO, A. M. F.; TATUMI, S. H.; SUGUIO, K; OLIVEIRA, P. E; AYTA, W. E. F. As dunas costeiras inativas do Rio Grande do Norte datadas por termoluminescência e implicações paleoambientais. In: CONGRESSO DAASSOCIAÇÃO BRASILEIRA DE ESTUDOS DO QUATERNÁRIO, 7., 1999. Porto Seguro. Resumo. Porto Seguro: ABEQUA, 1999. 1 CD-ROM.

BARRETO, A. M. F., SUGUIO, K.; BEZERRA, F. H. R. Late Pleistocene marine terrace deposits in northeastern Brazil: sea-level change and tectonic implications. Palaeogeography, Palaeoclimatology, Palaeoecology, Amsterdam, v. 179, p. 57-69, 2001a.

BARRETO, A. M. F.; SUGUIO, K.; ALMEIDA, J. A. C.; BEZERRA, F. H. R. A presença da icnoespécie Ophiomorpha nodosa Lundgren em rochas sedimentares pleistocênicas da costa norte-riograndense e suas implicações paleoambientais. Revista Brasileira de Paleontologia, v. 3, p. 17-23, 2001b.

BEZERRA, F. H. R.; LIMA-FILHO, F. P.; AMARAL, R. F.; CALDAS, L. H. O.; COSTA-NETO, L. X. Holocene coastal tectonics in NE Brazil. In: STEWART, I.; VITA-FINZI, C. (Eds.) Coastal tectonics. London, 1998. p. 279-293. (Geological Society London Special Publication, 146).

BEZERRA, F. H. R.; VITA-FINZI, C. How active is a passive margin? Paleoseismicity in northeastern Brazil. Geology, v. 28, p. 591-594. 2000.

BRANNER, J. C. The stone reefs of Brazil, their geological and geographical relations. Bulletin. Museum Comparative Zoology. Geological Series 7, v. 44, 1904.

DNPM/UFRN. DEPARTAMENTO NACIONAL DA PRODUÇÃO MINERAL. Mapa geológico do Estado do Rio Grande do Norte. Rio Grande do Norte, DNPM/UFRN, 1998. 1 mapa. Escala 1:50.000.

GIANNINIP.C. BARRETO,A. M.F.; SUGUIO, K.; TATUMI, S. H. Idade TL e propriedades sedimentológicas na planície costeira do Rio Grande do Norte. In: CONGRESSO DA ASSOCIAÇÃO BRASILEIRA DE ESTUDOS DO QUATERNÁRIO, 7., 2001. Imbé. Anais... Imbé: ABEQUA, 2001. p. $135-136$.

GOMES, J. R. C.; GATTO, C. M. P. P.; SOUZA, G. M. C.; LUZ, D. S.; PIRES, J. L.; TEIXEIRA, W.; FRANÇA, F. A. B.; CABRAL, E. M. A.; MENOR, E. A.; MONTEIRO, N.; BARROS, M. J. G; RIBEIRO, E. G; LIMA, E. A.; FONSECA, R. A. Geologia. In: PROJETO RADAMBRASIL. Folhas SB. 24/25 Jaguaribe e Natal. Rio de Janeiro: MME, 1981. p. 27-300. (Levantamento de Recursos Naturais, v. 23).

LUCENA, L. R. F. Unidade Barra de Tabatinga - novas evidências de um paleodepósito quaternário de praia no 
litoral Potiguar. In: SIMPÓSIO DE GEOLOGIADO NORDESTE, 17., 1997. Fortaleza. Resumos Expandidos... Fortaleza: SBG-Núcleo Nordeste, 1997. p 168-171.

MELO, F. T. L. Aspectos morfo-dinâmicos do Complexo Lagunar Nísia Floresta - Papeba-Guaraíras, região costeira sul e oriental do RN. 2000. 75 f. Dissertação (Mestrado) - Universidade Federal do Rio Grande do Norte, Natal.

NOGUEIRA, A. M. B.; LIMA, M. S.; SALIM, J.; SÁ, J. M.; MANSO, V. A.V. Estudo das areias de dunas da faixa litorânea de Natal - Rio Grande do Norte. In: SIMPÓSIO DE GEOLOGIA DO NORDESTE, 7., 1975. Fortaleza. Boletim de Resumos... Fortaleza: SBG-Núcleo Nordeste, 1975. p. 39.

OLIVEIRA, M. I. M.; BAGNOLI, E.; FARIAS, C. C.; NOGUEIRA, A. M. B.; SANTIAGO, M. Considerações sobre a geometria, petrografia, sedimentologia, diagênese e idade dos beachrocks do Rio Grande do Norte. In: CONGRESSO BRASILEIRO DE GEOLOGIA, 36., 1990. Natal. Anais... Natal: SBG, 1990. v.2, p. 621-634.

PERRIN, P.; COSTA, M. I. P. As dunas litorâneas da região de Natal, RN. In: SIMPÓSIO DO QUATERNÁRIO DO BRASIL, 4., 1982. Rio de Janeiro. Atas... Rio de Janeiro: Cenpes-Petrobras, 1982. p. 291-304.

SILVA, C. Holocene stratigraphy and evolution of the Açu river delta, Rio Grande do Norte State, Brazil. 1991. (PhD) Thesis - Duke University, Durham.

SRIVASTAVA, N. K.; CORSINO, A. R. Os carbonatos de Touros (RN): petrografia estratigrafia. In: SIMPÓSIO DE GEOLOGIA DO NORDESTE, 11., 1984. Natal. Anais... Natal: SBG-NE, 1984. p. $165-176$.

SILVEIRA, J. D. Morfologia do litoral. In: AZEVEDO, A. de (Ed.) Brasil a terra e o homem. São Paulo: Companhia Editora Nacional, 1964. 305 p.

SUGUIO, K.; BARRETO, A. M. F.; BEZERRA, F. H. R. Barra de Tabatinga and Touros Formations: evidence for pleistocene hich sea level stillstands of the Rio Grande do Norte coast. Pesquisa em Geociências, Porto Alegre, v. 28 , p. $5-12,2001$.

TATUMI S. H.; COSTA, A. A.; BARRETO, A. M. F. Luminescência opticamente estimulada (LOE) de cristais de feldspato retirados de dunas costeiras do Rio Grande do Norte. In: CONGRESSO DA ABEQUA, 7., 1999. Porto Seguro. Resumos Expandidos... Porto Seguro: UFBA, 1999. 1 CD-ROM.

YEE, M.; TATUMI, S. H.; BARRETO, A. M. F.; MOMOSE, E. F.; PAIVA, R. P.; MUNITA, C.S. Thermoluminescence (TL) dating of inactive dunes from the Rio Grande do Norte Coast, Brazil. In: SIMPÓSIO BRASILEIRO SOBRE PRAIAS ARENOSAS: MORFODINÂMICA, ECOLOGIA, USOS, RISCOS E GESTÃO. 2000. Itajaí. Anais... Santa Catarina: UNIVALI, 2000. p.143-144. 